University of Nebraska - Lincoln

DigitalCommons@University of Nebraska - Lincoln

Sociology Department, Faculty Publications

Sociology, Department of

2006

Examining the Changing Influence of Predictors on Adolescent Alcohol Misuse

Kimberly A. Tyler

University of Nebraska-Lincoln, kim@ktresearch.net

Rosalie Torres Stone

University of Nebraska-Lincoln

Bianca Bersani

Examining the Changing Influence of Predictors on Adolescent Alcohol Misuse

Follow this and additional works at: https://digitalcommons.unl.edu/sociologyfacpub

Part of the Sociology Commons

Tyler, Kimberly A.; Torres Stone, Rosalie; and Bersani, Bianca, "Examining the Changing Influence of Predictors on Adolescent Alcohol Misuse" (2006). Sociology Department, Faculty Publications. 46. https://digitalcommons.unl.edu/sociologyfacpub/46

This Article is brought to you for free and open access by the Sociology, Department of at DigitalCommons@University of Nebraska - Lincoln. It has been accepted for inclusion in Sociology Department, Faculty Publications by an authorized administrator of DigitalCommons@University of Nebraska - Lincoln. 


\title{
Examining the Changing Influence of Predictors on Adolescent Alcohol Misuse
}

\author{
Kimberly A. Tyler \\ Rosalie Torres Stone \\ Bianca Bersani
}

\begin{abstract}
The purpose of this study was to examine whether the influence of key characteristics on adolescent alcohol misuse (i.e., maternal binge drinking, parenting, peers, school characteristics, and the adolescent's own behavior) change over time and whether predictors of adolescent alcohol misuse vary by gender and race/ethnicity. Using prospective, longitudinal data from a community sample, results revealed that mother's binge drinking, peer drinking, and an early age of onset predicted higher levels of alcohol misuse when respondents were 14-16 years of age. Two years later, when adolescents were 16-18 years of age, maternal binge drinking was no longer significant, however, maternal attachment, school attachment, peer drinking, and early age of onset
\end{abstract}

Kimberly A. Tyler, PhD, is Associate Professor, Rosalie Torres Stone, PhD, is Assistant Professor, and Bianca Bersani, MA, is Graduate Research Assistant; all are affiliated with Department of Sociology, University of Nebraska-Lincoln, Lincoln, NE.

Kimberly A. Tyler received her PhD in 1999 in Sociology from Iowa State University. Her major current research interests are homeless youth, mental health outcomes, and high risk behaviors. Rosalie Torres Stone received her PhD in 2000 in Sociology from The University of Connecticut. Her major research interests are social inequality, race and ethnicity, and substance use. Bianca Bersani received an MA in 2004 in Sociology from the University of Nebraska-Lincoln. Her major research interest is adolescent deviant behavior.

Address correspondence to: Kimberly A. Tyler, PhD, Associate Professor, The University of Nebraska-Lincoln, Department of Sociology, 717 Oldfather Hall, Lincoln, NE 68588-0324 (E-mail: kim@ktresearch.net).

Joumal of Child \& Adolescent Substance Abuse, Vol. 16(2) 2006

Available online at http://jcasa.haworthpress.com

(C) 2006 by The Haworth Press, Inc. All rights reserved.

doi: $10.1300 / J 029 \mathrm{v} 16 \mathrm{n} 02 \_05$ 
were found to significantly predict adolescent alcohol misuse. Race differences were found for maternal binge drinking and gender differences were found for school suspension and maternal monitoring on adolescent drinking. doi:10.1300/J029v16n02_05/Article copies available for a fee from The Haworth Document Delivery Service: 1-800-HAWORTH. E-mail address: <docdelivery@haworthpress.com> Website: <http://nww.HaworthPress. com> (c) 2006 by The Haworth Press, Inc. All rights reserved.]

KEYWORDS. Alcohol misuse, risk factors, adolescents

\section{INTRODUCTION}

Adolescence is a period in which many young people experiment with and/or initiate alcohol use. Age of onset typically occurs between 13 and 15 years of age and the majority of young people under age 18 have consumed alcohol (O'Malley, Johnston, \& Bachman, 1998). Although some adolescents may only experiment at first, the earlier alcohol use begins, the greater the risk that young people will eventually engage in problem behaviors such as delinquency, school failure, and substance abuse (Hawkins, Catalano, \& Miller, 1992; Kaplow, Curran, \& Dodge, 2002).

Patterns and prevalence of alcohol use have been found to vary by gender and race/ethnicity among adolescents. According to the Substance Abuse and Mental Health Services Administration (SAMHSA), even though rates of lifetime, past-year, and past-month use of alcohol are similar among 12-17 years old males and females, males tend to have higher rates of binge drinking and heavy alcohol use. Additionally, among those 12-17 years old, the highest rates of alcohol use in the past month were found among whites (20\%), followed by Hispanics (17\%), and then African Americans (11\%) (SAMHSA, 2002). Such findings are consistent with O'Malley and colleagues (1998) who report that alcohol consumption is generally found to be highest among white youth.

Although numerous studies have looked at the individual effects of several important characteristics such as family and peers on adolescent alcohol use (cf. Anderson \& Henry, 1994; Dinges \& Oetting, 1993), fewer studies have investigated the changing impact of these characteristics on adolescent alcohol use over time due to cross-sectional research designs. Additionally, although prevalence rates have been found to vary by specific groups (SAMHSA, 2002), less is known about 
whether gender and race/ethnicity moderates the relationship between risk factors and adolescent alcohol misuse. In sum, researchers have called for examining a multitude of factors that may simultaneously influence adolescents' alcohol behavior over time (Wills \& Yaeger, 2003; Windle, 1996). To address these research gaps, we use a prospective, longitudinal, community sample of mothers and their adolescent children to examine whether the influence of key characteristics on adolescent alcohol misuse (i.e., maternal binge drinking, parenting, peers, school characteristics, and the adolescent's own behavior) change over time. Additionally, given potential differences in heavy drinking and binge drinking by gender and race/ethnicity, we test the extent to which predictors of adolescent alcohol misuse vary among these groups.

\section{LITERATURE REVIEW}

Parent and Peers. The importance of parent and peer influence on adolescent substance use has been well documented (Anderson \& Henry, 1994; Ary et al., 1993; Brook et al., 1989; Dinges \& Oetting, 1993; Hawkins et al., 1992) and the research reveals that good relations with parents can serve as a protective factor for youth. For example, effective parenting and a good relationship with parents are important in preventing alcohol misuse among adolescents (Barnes, Reifman, Farrell, \& Dintcheff, 2000; Ledoux et al., 2002).

Other studies, however, indicate that the influence of peers tends to be much stronger than parental influences (Cumsille, Sayer, \& Graham, 2000; Flannery et al., 1994; Kandel \& Andrews, 1987). For example, Flannery and associates (1994) found that the most powerful predictor of adolescent substance use was having close friends who drink and experiencing pressure from peers to engage in antisocial behavior. Similarly, Epstein and colleagues found that the odds of drinking were almost triple for youth who reported that more than half of their friends drank (Epstein, Botvin, \& Diaz, 1995). Other research, however, has found that the importance of parents and peers varies by adolescent age. Barber, Bolitho, and Bertrand (1998) found, for example, that friends' drinking had a stronger influence on youth 16-17 years of age than it did for those who were 14-15 (Barber et al., 1998). Strycker, Duncan, and Pickering (2003) found that early initiators of alcohol were more likely to be at home with their families whereas later initiators were more likely to be with friends. This suggests that some parents who drink may initially introduce their children to alcohol-using behavior, but for 
youth who have not been exposed to family drinking, initiation may occur later in life through the influence of friends.

Parental Binge Drinking. Research also finds that parental substance abuse is an important predictor of adolescent alcohol use (Windle, 1996). According to a study by Kaplow and colleagues (2002), parental substance abuse was associated with a greater likelihood of their kindergarten-aged children using substances by the time they reach the sixth grade. Parents' own use of substances was also the single strongest predictor of children's early initiation into substance use (Kaplow et al., 2002). Conger and Rueter (1996) also found that mother's history of substance use problems was positively related to adolescent alcohol use.

Deviant Behavior. Participating in deviant behavior has also been linked to alcohol use (Brook et al., 1986; Fergusson, Lynskey, \& Horwood, 1996). In one study of over 900 youth (ages 15-16), those who were classified as misusing alcohol were significantly more likely to report higher rates of violent offenses and property offenses (Fergusson et al., 1996). Brook and colleagues (1986) also found that students who used alcohol on a regular basis were more likely to report self-deviance.

School Attachment. A negative experience with school is another risk factor for substance use (Bryant et al., 2003). Adolescents who have less commitment to school and/or are not doing very well in school are at greater risk for participation in delinquency and/or substance use (Mason \& Windle, 2001) whereas attachment and commitment to school lowers the risk for alcohol abuse and dependency (Guo et al., 2001).

Age of Onset. According to O'Malley and colleagues (1998) alcohol initiation typically occurs between 13 and 15 years of age and the earlier children initiate the use of alcohol, the greater their risk of engaging in problem behaviors such as delinquency, school failure, and substance abuse (Hawkins et al., 1992; Kaplow et al., 2002). Several studies have found support for the association between an earlier age of onset and problem behavior (cf. Hawkins et al., 1996; Lo, 2000; Zhang, Wieczorek, \& Welte, 1997).

Background Variables. Males have been found to have a higher frequency of alcohól use, to drink more heavily, and to initiate use earlier compared with females (Barnes, Welte, \& Hoffman, 2002; Cardenal \& Adell, 2000; Mason \& Windle, 2001; Thomas et al., 2000). Race differences have also been reported with whites having higher rates of alcohol misuse and intoxication (Barnes \& Welte, 1986; Johnston, O'Malley, \& Bachman, 1999; Paschall, Flewelling, \& Faulkner, 2000; Thomas et al., 
2000) as well as initiating alcohol use at younger ages compared with African Americans (Strycker et al., 2003). Family structure has also been linked to problem behaviors (Barnes et al., 2002; Thomas et al., 2000). It is believed that single-parent families provide lower supervision; therefore, adolescents in such families are at higher risk for alcohol misuse. Finally, lower socioeconomic status has been associated with lower rates of alcohol use (Epstein et al., 1999).

\section{Theoretical Perspective}

Although numerous theories on adolescent substance use exist (cf. Petraitis, Flay, \& Miller, 1995), the current study proposes a social learning approach (Akers, 1977) to explain adolescent alcohol misuse because it accounts for both parental and peer influences (cf. Kaplow et al., 2002). According to Akers (1977), moderate drinking is a socially accepted adult behavior and is part of the conventional socialization into adult roles. Underage drinking, according to Akers (1977), "is behavior learned in conventional settings. Initial drinking behavior is conditioned most strongly by parental influence . . ." (149). As such, adolescents who are exposed to parents drinking in moderation may learn to drink responsibly as they become adults. Adolescents who have parents with severe alcohol and/or drug problems, however, may be at risk for imitating or modeling this unhealthy behavior. That is, adolescents may initially become involved in alcohol and/or drugs by observing the behavior of their family members. Others who are not exposed to alcohol misuse by family members, however, may be introduced to it by their peers. According to Akers (1977), "drinking-centered groups" are more likely to accept and legitimate alcohol use as normative behavior. Additionally, using alcohol is likely to be rewarded (i.e., acceptance into the group) and non-compliance is likely to be negatively sanctioned (e.g., name-calling, exclusion from the group), given the strong pressure from other group members to engage in alcohol use.

\section{Hypotheses}

Although the literature has examined risk factors for alcohol use, fewer studies have focused on the simultaneous influence of numerous characteristics, especially over time. Therefore, based on the literature, we hypothesize that a multitude of factors (i.e., maternal binge drinking, parenting, peers, school characteristics, and adolescents' own behavior) will be associated with adolescent alcohol misuse and that the influence 
of these characteristics will change over time. Additionally, given differences in prevalence rates, we hypothesize that race and gender may moderate these relationships.

\section{METHODS}

\section{Data}

Analyses are based on data from the National Longitudinal Survey of Youth-Young adult data (NLSY79). The original NLSY79 cohort is a nationally representative longitudinal sample of youth aged 14-21 in 1979. The NLSY79 contains extensive information on numerous topics including employment, education, training, and family experiences. Since 1986, assessments and interviews of the children born to the women of the NLSY79 were conducted in order to obtain specific information on their development (see Center for Human Resource Research User's Guide, 2001). According to the User's Guide "[T]he children of the NLSY79 mothers have been independently followed and interviewed in various ways starting in 1986" (Center for Human Resources Research User's Guide, 2000, p. 5). Since 1988, children aged ten and over have completed extensive self-report questionnaires that contain sensitive information regarding their attitudes and behaviors including: parent-child interactions, general attitudes, and substance use behaviors. Starting in 1994, respondents aged 15 and older (young adults) completed individual, personal interviews that focus on a variety of attitudes and behaviors (see Center for Human Resource Research User's Guide, 2001).

The NLSY79 child and young adult sub-samples are a nationally representative sample of children born to women who were between the ages of 14 and 21 on December 31, 1978. Data for the present analyses were taken from the child assessments in 1994 when the youth were 12-14 years of age, from the young adult assessments in 1996 when the youth were 14-16 years of age, and in 1998 when the youth were 16-18 years of age. The independent variables (e.g., background characteristics, parental characteristics, and environmental characteristics) were measured in 1994 (with the exception of maternal binge drinking, which was measured in 1992). The mediators (deviant behavior, school attachment, and peer drinking) and age of onset were measured in 1996, while the dependent variables (adolescent alcohol consumption) were measured in 1996 and 1998. The original sample violated independence 
assumptions because siblings were included in the sample. To rectify this, one respondent was randomly selected out of each sibling group for inclusion in the final sample.

\section{Missing Data}

The present research began with a sample size of 542 respondents. Only those cases with complete data were retained for the analyses. Potential bias due to missing cases with incomplete data was assessed by comparing the control and predictor variables of the cases with missing data in the analyses with those cases with complete data $(n=244)$. A series of $\chi^{2}$ and $t$ tests were estimated for this purpose. Results indicate that non-whites $\left(\chi^{2}{ }_{1 \mathrm{df}}=4.293, \mathrm{p}<.05\right)$, respondents whose mothers did not obtain a high school education $(t=2.775, \mathrm{p}<.01)$, and respondents with low levels of maternal monitoring $(t=2.345, \mathrm{p}<.05)$ were more likely to be missing from the analyses. Given these findings, the results should be interpreted somewhat cautiously.

\section{Measures}

See Table 1 for a list of all means, standard deviations, and ranges for study variables.

Dependent Variables. Adolescent alcohol misuse is a constructed variable measuring the severity of drinking behaviors in both 1996 and 1998. Two variables were combined to construct the alcohol misuse variable. First, a variable was constructed to compare those adolescents who reported never consuming alcohol with those who reported ever consuming alcohol. Respondents who reported ever drinking were then asked how often in the past 30 days they consumed five or more drinks on the same occasion. This item was collapsed into a dichotomous variable $0=$ never consumed five or more drinks on the same occasion; $1=$ consumed five or more drinks on the same occasion. These two variables were then combined; respondents who never drank alcohol were coded as 0 , respondents who had drunk alcohol but did not classify as a binge drinker (i.e., had never consumed five or more drinks on the same occasion) were coded as 1 , and respondents who drank alcohol and had consumed five or more drinks on the same occasion (i.e., binge drinkers) were coded as 2 . Nearly $11 \%$ of the respondents in 1996, and $17 \%$ of the respondents in 1998, were classified as binge drinkers. 
TABLE 1. Descriptive Statistics for All Study Variables

\begin{tabular}{lrrrr}
\hline & \multicolumn{2}{c}{1996} & \multicolumn{2}{c}{1998} \\
\cline { 2 - 5 } & Mean & SD & Mean & SD \\
\hline Gender (1 = female) & .502 & .501 & .496 & .501 \\
Race (1 = white) & .474 & .500 & .467 & .500 \\
Family structure (1 = intact) & .435 & .497 & .422 & .495 \\
Mother's education (0-2) & 1.004 & .753 & 1.053 & .732 \\
Maternal binge drinking (1 = binger) & .077 & .267 & .090 & .287 \\
Maternal attachment (-8.89 to 3.62) & .044 & 2.782 & .024 & 2.771 \\
Maternal monitoring (1-4) & 1.333 & .535 & 1.332 & .514 \\
Peer pressure (0-5) & .428 & .996 & .455 & .995 \\
School suspension (1 = suspended) & .175 & .381 & .172 & .378 \\
Deviant behavior (0-4) & 1.211 & 1.479 & 1.234 & 1.493 \\
School attachment (6-24) & 19.311 & 2.933 & 19.369 & 2.714 \\
Peer drinking (0-4) & 1.407 & 1.249 & 1.467 & 1.255 \\
Age of onset (1 = early onset) & .260 & .439 & .299 & .459 \\
Adolescent alcohol misuse 1996 (0-2) & .526 & .684 & - & - \\
Adolescent alcohol misuse 1998 (0-2) & - & - & .775 & .722 \\
\hline
\end{tabular}

Mediator Variables. The mediator variables included in the present study were measured in 1996 and included measures of deviant behavior, school attachment, and peer drinking.

Deviant behavior was measured using 13 items. The questions focused on criminal activities that adolescents may have engaged in during the past year such as stealing something from a store, damaging the property of others, breaking into a building, and trying to con someone. The items were coded 0 "no" and 1 "yes." The 13 items were summed, but because the variable was highly skewed, it was recoded into $0=$ none, $1=$ had done one of these things; 2 = had done two of these things; $3=$ had done three of these things; and $4=$ had done four or more of these things. Cronbach's alpha for deviant behavior was .81 .

School attachment was a composite index of six items measuring the youth's bond to academics. Respondents were asked if their teachers help them with personal problems, if their teachers know their subjects well, if their school requires the best of their abilities, if they have the 
freedom to learn what interests them, if the school offers good job counseling, and how satisfied they are with school. Items were recoded so that a high score indicated greater attachment to school. Cronbach's alpha for this measure was .69 .

Peer drinking was a single-item measure that asked respondents how many of the people their age that they hang around with drink at least sometimes. Response categories ranged from 0 "none" to 4 "all of them." Only $26 \%$ of adolescents said that none of the friends they hang out with drink; $39 \%$ said a few of them drink; $10 \%$ said half of them drink; $18 \%$ said most of them drink, and $7 \%$ of adolescents reported that all of the friends that they hang out with drink alcohol at least sometimes.

Independent Variables. The independent variables included maternal binge drinking, which was measured in 1992, parent child relations and environmental characteristics, which were measured in 1994, and age of onset, measured in 1996.

Maternal binge drinking was a single item measuring mothers' alcohol consumption in 1992. Mothers of the respondents were asked how many drinks they had consumed per day in the last 30 days. This item was collapsed into $0=$ never drank, or consumed no more than four drinks in a day in the past 30 days; $1=$ consumed more than five drinks in a single day (binge drinker during the last 30 days). Nearly $8 \%$ of the respondent's mothers were classified as binge drinkers.

Maternal attachment was a composite index of four items measuring parent-child affective bonds. Children were asked how close they felt towards their mother and how well they (mother and child) share ideas, coded 1 = not very close/not very well; $4=$ extremely close/extremely well. The children were also asked how often their mothers talked over important decisions with them and how often their mother listened to their side of an argument. Responses ranged from $1=$ hardly ever to $3=$ often. The four items were standardized due to different response categories and then summed. Cronbach's alpha for this measure was .68.

Maternal monitoring was a single item assessing mother's knowledge of who their child was with when away from home. Responses were recoded so that a high score indicated high monitoring with a range of $1=$ only rarely knows to $4=$ knows all of the time.

Peer pressure was a composite scale of five self-report items measuring the pressure the child feels from peers to try cigarettes, to try marijuana, to drink alcohol, to skip school, or to commit a crime. The items were summed and responses ranged from $0=$ feels no pressure to $5=$ feels pressure to commit all acts. Cronbach's alpha for peer pressure was .75 . 
School suspension was a single item indicator measuring whether the child was ever suspended from school. The item was coded $0=$ no; $1=$ yes. Nearly $18 \%$ of the respondents had been suspended from school at least once.

Age of onset was a self-reported item of how old respondents were when they first had a glass/drink of beer, wine, or liquor. Because literature generally uses 13 years of age as the cutoff delineating early onset (cf. Lo, 2000; Zhang et al., 1997), this item was assessed in the 1996 wave so that all of the respondents would be past this important marker. Just over one-quarter $(26 \%)$ of the sample reported an early onset of first alcohol consumption.

Background variables included gender, race, family structure, and mother's education. Gender was coded $0=$ male; $1=$ female and the sample was evenly split by gender. Race was coded $0=$ non-white (African Americans and Hispanics); $1=$ white. The sample was predominantly non-white $(53 \%)$. Family structure measured whether children lived with both biological parents (coded as 1) or in other familial arrangements (coded as 0). Mother's education, which was used as a proxy of socioeconomic status, was a single item measuring the highest grade completed by the respondent's mother in 1994. This item was collapsed so that $0=$ did not graduate high school; $1=$ graduated from high school; and $2=$ obtained some post-secondary education/training. A total of $28 \%$ of mothers reported not graduating from high school, $44 \%$ reported graduating from high school, and $28 \%$ reported obtaining some post-secondary education/training.

\section{RESULTS}

Table 2 presents the results for predictors of adolescent alcohol misuse for 1996 using stepwise multiple regression in SPSS (Version 11.5). In Model 1 , race $(\beta=.137)$ and maternal binge drinking $(\beta=.235)$ were positively associated with alcohol misuse (when adolescents were 1416 years of age) indicating that whites and those whose mothers reported binge drinking were more likely to report alcohol misuse. Model 1 explained approximately $8 \%$ of the variance.

In Model 2 (Table 2 ) race $(\beta=.140)$ and maternal binge drinking $(\beta=$ .233) remained significant but the addition of the parent-child relations variables (i.e., attachment and monitoring) were not significant. The parenting measures remained non-significant in all subsequent models. The next model (Model 3), which added youth's environmental charac- 
TABLE 2. Multiple Regression Models for Predictors of Alcohol Misuse (1996)

\begin{tabular}{|c|c|c|c|c|c|}
\hline & $\begin{array}{c}\text { Model } 1 \\
\beta\end{array}$ & $\begin{array}{c}\text { Model } 2 \\
\beta \\
\end{array}$ & $\begin{array}{c}\text { Model } 3 \\
\beta \\
\end{array}$ & $\begin{array}{c}\text { Model } 4 \\
\beta \\
\end{array}$ & $\begin{array}{c}\text { Model } 5 \\
\beta \\
\end{array}$ \\
\hline \multicolumn{6}{|l|}{ Background variables } \\
\hline Gender $(1=$ female $)$ & .031 & .035 & .057 & .071 & .033 \\
\hline Race/ethnicity ( $1=$ white $)$ & $.137^{*}$ & $.140^{*}$ & $.154^{* *}$ & .089 & .029 \\
\hline Family structure $(1=$ intact $)$ & -.077 & -.075 & -.032 & .009 & .014 \\
\hline Mother's education (0-2) & -.065 & -.064 & -.041 & -.062 & -.028 \\
\hline Maternal binge drinking ( $1=$ binger $)$ & $.235^{* *}$ & $.233^{\star \star}$ & $.221^{\star *}$ & $.200^{* *}$ & $.171^{* *}$ \\
\hline \multicolumn{6}{|l|}{ Parent-child relations } \\
\hline Maternal attachment & & .020 & .023 & .021 & .043 \\
\hline Maternal monitoring & & .020 & -.026 & -.066 & -.072 \\
\hline \multicolumn{6}{|l|}{ Environmental characteristics } \\
\hline Peer pressure & & & $.213^{* *}$ & $.145^{\star \star *}$ & .069 \\
\hline School suspension & & & $.175^{\star \star}$ & $.125^{\star \star \star}$ & .077 \\
\hline \multicolumn{6}{|l|}{ Mediators-1996 } \\
\hline Deviant behavior & & & & .082 & .054 \\
\hline School attachment & & & & -.040 & -.020 \\
\hline Number of friends who drink alcohol & & & & $.411^{* *}$ & $.312^{\star *}$ \\
\hline \multicolumn{6}{|l|}{ Age of onset } \\
\hline Onset in 1996 ( 1 = early) & & & & & $.398^{* *}$ \\
\hline Adjusted $R^{2}$ & .075 & .069 & .137 & .334 & .459 \\
\hline
\end{tabular}

$N=285 .{ }^{*} p=.05,{ }^{* *} p=.01$.

teristics, revealed that those who experienced greater peer pressure $(\beta=$ $.213)$ and those who have ever been suspended from school $(\beta=.175)$ were likely to report higher alcohol misuse. Whites $(\beta=.154)$ and those with a mother who was a binge drinker $(\beta=.221)$ also were likely to exhibit higher alcohol misuse. Model 3 explained 14\% of the variance in the outcome variable.

In Model 4, with the addition of the mediators (1996), the explained variance jumped from 14 to $33 \%$ in this model. Maternal binge drinking continued to be a strong predictor of adolescents' alcohol misuse $(\beta=$ $.200)$. Peer pressure $(\beta=.145)$ and suspension from school $(\beta=.125)$ 
were also significant. Having a greater number of friends who drink alcohol $(\beta=.411)$ was also a strong predictor of adolescents' own alcohol misuse. Deviant behavior and school attachment were not significant.

Finally, in Model 5, even when controlling for age of onset, maternal binge drinking ( $\beta=.171$ ) remained significant. Number of friends who drink alcohol was also significant $(\beta=.312)$ and those who had an early age of onset of drinking were significantly more likely to report alcohol misuse $(\beta=.398)$. Age of onset significantly increased the variance explained from 33\% in Model 4 to $46 \%$ in Model 5.

In order to test whether gender and race/ethnicity moderated these relationships, a total of 16 interactions ( 8 for gender and 8 for race/ethnicity), were added one at a time into the main effects model (Model 5; Table 2). The results for the race interactions (not shown) revealed that race $\times$ maternal binge drinking $(\beta=.194 ; p=.009)$ was significant. As seen in Figure 1, the effect of maternal binge drinking had little effect on adolescent alcohol misuse for non-whites. Alcohol misuse increased, however, among white adolescents with binge drinking mothers.

The gender interactions (also for Model 5; Table 2 ) revealed that gender $\times$ school suspension was significant $(\beta=.163 ; p=.011)$. As seen in Figure 2, alcohol misuse was likely to increase for females who had been suspended from school. Suspension, however, had little effect on adolescent alcohol misuse for males.

Since we were interested in seeing whether the influence of predictors (e.g., maternal binge drinking) change as adolescents get older, we present the stepwise multiple regression models for predictors of adolescent alcohol misuse for 1998 in Table 3. In Models 1 through 4, race/ ethnicity was a significant predictor of alcohol misuse with whites re-

FIGURE 1. Race by maternal binge drinking 1992.

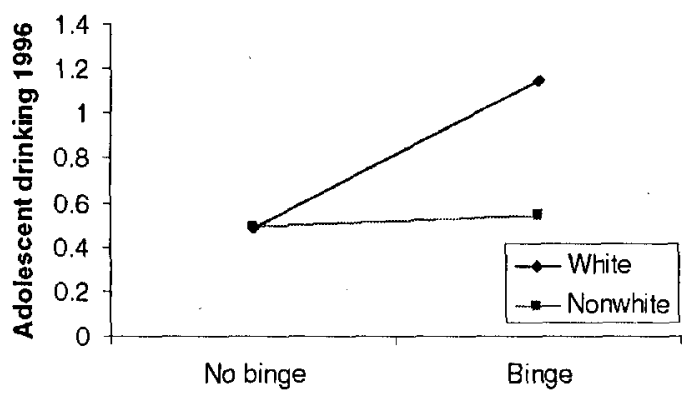

Maternal binge drinking 
FIGURE 2. Gender by school suspension.

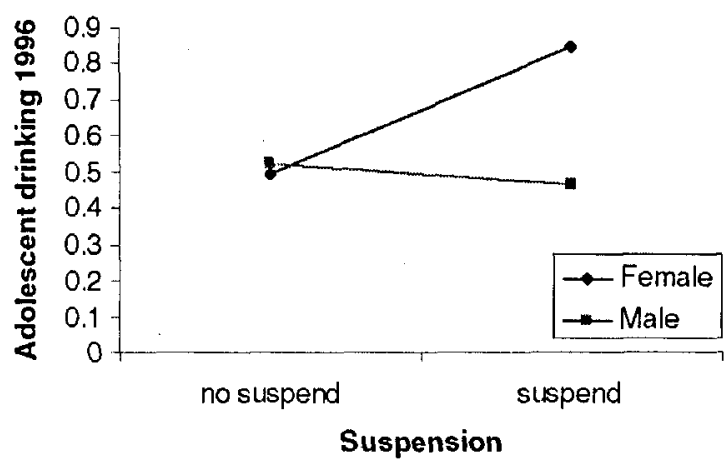

porting more misuse compared with their non-white counterparts. Maternal binge drinking no longer predicted alcohol misuse in 1998 (when respondents were 16-18 years of age). In Model 2, maternal attachment was significant indicating that youth with lower attachment were more likely to have greater alcohol misuse $(\beta=-.136)$. Model 2 explained approximately $7 \%$ of the variance in the outcome variable. In Model 3, race/ethnicity and maternal attachment remained significant. Peer pressure was also significant $(\beta=.147)$ indicating that youth who experienced greater pressure to engage in high risk behaviors were more likely to have higher rates of alcohol misuse.

In Model 4, controlling for the mediators increased the variance from $9 \%$ to almost $27 \%$. Both school attachment $(\beta=-.113)$ and friends drinking $(\beta=.355)$ were significant indicating that those who have lower school attachment and those who have a greater number of friends who drink were more likely to report greater alcohol misuse. Controlling for age of onset in Model 5 increased the variance from 27 to $33 \%$. Early age of onset $(\beta=.291)$, low maternal attachment $(\beta=$ $-.106)$, low attachment to school $(\beta=-.105)$, and having a greater number of friends who drink $(\beta=.285)$ were all significant predictors of alcohol misuse.

In order to test whether risk factors differed by gender and race/ethnicity when youth were 16-18 years of age, a total of 16 interactions ( 8 for gender and 8 for race/ethnicity), were added one at a time into the main effects model (Model 5; Table 3). The results revealed no significant race interactions (results not shown). However, gender $\times$ monitoring was significant $(\beta=-.304 ; p=.041)$. As seen in Figure 3, females had higher rates of alcohol misuse compared to males. As rates of moni- 
TABLE 3. Multiple Regression Models for Predictors of Alcohol Misuse (1998)

\begin{tabular}{|c|c|c|c|c|c|}
\hline & Model 1 & Model 2 & Model 3 & Model 4 & Model 5 \\
\hline & $\beta$ & $\beta$ & $\beta$ & $\beta$ & $\beta$ \\
\hline \multicolumn{6}{|l|}{ Background variables } \\
\hline Gender ( 1 = female $)$ & .058 & .077 & .100 & .111 & .086 \\
\hline Race/ethnicity ( 1 = white) & $.211^{* *}$ & $.196^{\star *}$ & $.197^{\star \star}$ & $.139^{*}$ & .101 \\
\hline Family structure (1 = intact) & -.076 & -.067 & -.035 & .008 & .005 \\
\hline Mother's education (0-2) & -.019 & -.033 & -.023 & -.037 & -.007 \\
\hline $\begin{array}{l}\text { Maternal binge drinking } \\
(1=\text { binger })\end{array}$ & .105 & .105 & .097 & .086 & .061 \\
\hline \multicolumn{6}{|l|}{ Parent-child relations } \\
\hline Maternal attachment & & $-.136^{*}$ & $-.132^{\star}$ & $-.119^{*}$ & $-.106^{\star}$ \\
\hline Maternal monitoring & & .114 & .091 & .047 & .035 \\
\hline \multicolumn{6}{|l|}{ Environmental characteristics } \\
\hline Peer pressure & . & & $.147^{\star}$ & $.110^{\star}$ & .062 \\
\hline School suspension & & & .104 & .040 & .021 \\
\hline \multicolumn{6}{|l|}{ Mediators-1996 } \\
\hline Deviant behavior & & & & .093 & .059 \\
\hline School attachment & & & & $-.113^{*}$ & $-.105^{\star}$ \\
\hline $\begin{array}{l}\text { Number of friends who drink } \\
\text { alcohol }\end{array}$ & & & & $.355^{\star \star}$ & $.285^{\star \star}$ \\
\hline
\end{tabular}

\section{Age of onset}

Onset in 1996 ( 1 = early)

$291^{* *}$

Adjusted $\mathrm{R}^{2}$

toring increased, however, there was a slight decrease in alcohol misuse for females but a slight increase for males.

\section{DISCUSSION}

We proposed to answer two key questions with our analyses of adolescent alcohol misuse. First, do predictors of adolescent alcohol misuse change over time? Second, do these predictors of adolescent alcohol 
FIGURE 3. Gender by maternal monitoring.

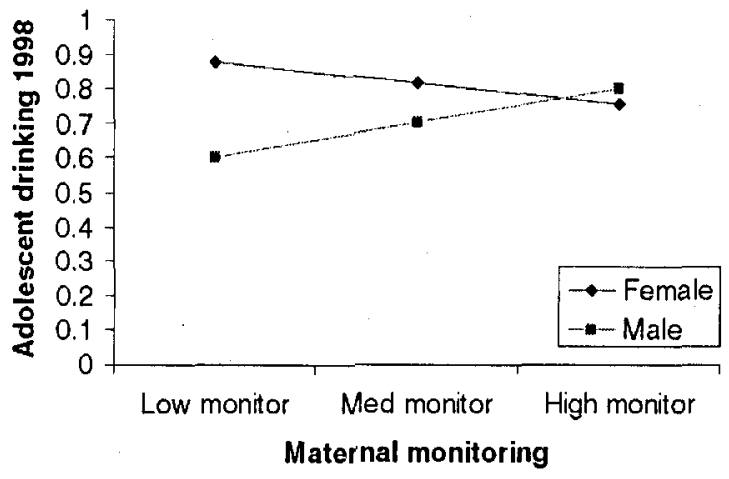

misuse vary by gender and race/ethnicity? In response to the first question, some unique differences do exist depending on the age of the adolescent. Mother's binge drinking and school suspension were strong predictors of adolescent's own alcohol misuse when they were 14-16 years of age but were no longer significant predictors two years later. In contrast, a strong maternal attachment and school attachment lowered the risk for alcohol misuse when youth were 16-18 years of age but not at earlier ages. Having a greater number of friends who drink, peer pressure, and early age of onset of alcohol use remained significant over time. To answer our second question, some predictors of alcohol misuse varied by race and gender. Maternal binge drinking had a greater effect for whites than non-whites. In terms of gender, although higher maternal monitoring lowered the risk of alcohol misuse for females, being suspended from school increased their risk.

Although research has found that parental and/or maternal alcohol problems are important predictors of adolescent alcohol misuse (Conger \& Rueter, 1996; Kaplow et al., 2002; Windle, 1996) the current study finds that maternal binge drinking was most significant during early rather than later adolescence, suggesting that mothers serve as important role models early on. According to Conger and Rueter (1996), for white adolescents, substance abuse among mothers is less common than among fathers, and maternal involvement with alcohol may serve to legitimize this behavior for youth more so than the substance abuse of fathers. Additionally, because mothers are generally more responsible for child rearing, they are likely to serve as important role models for their young children. Another interesting finding was that the effect of maternal binge drinking varied by race/ethnicity such that binge drink- 
ing had little effect on non-whites but it led to an increase in alcohol misuse among white youth. Since Conger and Rueter only looked at white adolescents, we cannot compare our results with theirs regarding non-whites. It is possible that the normative expectations surrounding drinking differ by race/ethnic groups. Non-white adolescents may associate drinking with negative outcomes such as accidents and health problems; therefore, they may be less likely to model their mother's behavior. Additionally, we do not know if the mother is drinking alone or with other people. Therefore, the social context in which family members drink may also differ for whites and non-whites and may lead to different outcomes.

Although research finds that effective parenting and a good relationship with parents is important in preventing alcohol misuse among adolescents (Barnes et al., 2000; Ledoux et al., 2002), we found that this changes over time. Maternal attachment was only significant when respondents were 16-18 years of age. Since our maternal attachment measure is an indicator of how well the children communicated with their mothers, it is possible that at older ages this becomes more important given the greater influence of peers and exposure to deviant behaviors. Mothers who maintain open communication with their children are more likely to prevent alcohol misuse at this age.

Given that adolescence is a time when many young people resist parental authority and spend a significant amount of time with their friends (Steinberg \& Silverberg, 1986) the influence of peers becomes increasingly important (Cumsille et al., 2000; Kandel \& Andrews, 1987). Consistent with previous research (Flannery et al., 1994), the current results reveal that pressure from friends to engage in antisocial behavior and having close friends who drink are powerful predictors of adolescent alcohol misuse regardless of age. It is possible that since mother's binge drinking was measured in 1992 when respondents were approximately 10-12 years of age, the behavior set normative expectations and legitimized drinking. As a result, these youth were free to associate with same age peers who also drank (cf. Conger \& Rueter, 1996).

Being suspended from school was only predictive of alcohol misuse among those 14-16 years old, whereas low school attachment was only predictive when respondents were 16-18 years of age. Adolescents who are suspended from school may have lower commitment and less interest in school and become less attached over time. Therefore, as adolescents become older, school attachment may increase in importance and serve as a buffer against alcohol misuse. Our interaction revealed that 
for females, being suspended from school was associated with higher alcohol misuse, whereas there was little effect for males. This gender difference may be explained by the fact that both school suspension and alcohol misuse may be more normative for males than for females. Females who have been suspended were perhaps more likely to have exhibited other antisocial behaviors such as alcohol consumption.

The fact that an earlier age of onset was predictive of greater alcohol misuse is also consistent with previous findings (Hawkins et al., 1992; Kaplow et al., 2002). Additionally, our results revealed that earlier onset is associated with alcohol misuse regardless of gender and race/ ethnicity.

Consistent with a social learning approach, initial drinking behavior does appear to be strongly influenced by mother's alcohol misuse. Adolescents who are exposed early on to mothers' binge drinking are at risk for imitating or modeling this unhealthy behavior. If mothers engage in this behavior on a regular basis, the activity may become legitimized and may lead some adolescents to form ties with other alcohol-using friends. According to Akers (1977), these "drinking-centered groups" are more likely to accept and legitimate alcohol use as normative behavior, which may be an extension of what some adolescents were exposed to in their families. On the other hand, adolescents who did not experience maternal binge drinking may be later exposed to pressure from friends to engage in an array of antisocial behavior, including alcohol misuse. Our results suggest that at younger ages, adolescents are more likely to be influenced by their mother's drinking. At older ages, however, the drinking behavior of peers becomes the pivotal factor in adolescent drinking behavior.

There are both strengths and limitations of this study. The longitudinal data with both mother and adolescent reports and the fact that this data set contains respondents from across the country rather than being limited to a specific city or area are strengths of this research. In addition, given the call for longitudinal data to examine a multitude of factors that may simultaneously influence adolescents' alcohol behavior, we examined across time numerous predictors of adolescent alcohol misuse and tested for moderating effects. We believe this research adds important insight into the changing influence of predictors of adolescent alcohol misuse. Some of the limitations associated with the use of secondary data include the lack of some important predictors of adolescent alcohol misuse such as harsh parenting. Additionally, some of our indicators (e.g., maternal monitoring) were single-item indicators which may have accounted for a lack of significance with our outcome vari- 
ables. Finally, with large data sets comes some level of attrition, which we discussed earlier under missing data.

In summary, our results indicate that the influence of certain predictors on adolescent alcohol misuse do change over time. Mothers' binge drinking, peer drinking, and an early age of onset predict higher levels of alcohol misuse when respondents were 14-16 years of age. Two years later, when adolescents were 16-18 years of age, maternal binge drinking was no longer significant, however, maternal attachment, school attachment, peer drinking, and early age of onset significantly predicted alcohol misuse. There was a significant race effect for maternal binge drinking and significant gender effects for school suspension and maternal monitoring on adolescent drinking. Using longitudinal data, future research should continue to explore the changing influence of a multitude of factors (including those not reported here) as well as implementing multiple indicator measures since we may see a different pattern. Additionally, researchers should test for moderating effects across time to see if similar results can be replicated for maternal binge drinking and race/ethnicity. More research is needed that focuses on the specific cultural context in which parents drink and the normative expectations that surround parent and adolescent drinking behavior.

\section{REFERENCES}

Akers, R. L. (1977). Deviant behavior: A social learning approach. Belmont, CA: Wadsworth Publishing Company, Inc.

Anderson, A. R., \& Henry, C. S. (1994). Family system characteristics and parental behaviors as predictors of adolescent substance use. Adolescence, 29, 405-420.

Ary, D. V., Tildesley, E., Hops, H., \& Andrews, J. (1993). The influence of parent, sibling, and peer modeling and attitudes on adolescent use of alcohol. The International Journal of the Addictions, 28, 853-880.

Barber, J. G., Bolitho, F., \& Bertrand, L. D. (1998). Age and gender differences in the predictors of adolescent drinking. Social Work Research, 22, 164-172.

Barnes, G. M., Reifman, A. S., Farrell, M. P., \& Dintchelf, B.A. (2000). The effects of parenting on the development of adolescent alcohol misuse: A six-wave latent growth model. Journal of Marriage \& the Family, 62, 175-186.

Barnes, G. M., \& Welte, J. W. (1986). Adolescent alcohol abuse: Subgroup differences and relationships to other problem behaviors. Journal of Adolescent Research, 1 , 79-94.

Barnes, G. M., Welte, J. W., \& Hoffman, J. H. (2002). Relationship of alcohol use to delinquency and illicit drug use in adolescents: Gender, age, and racial/ethnic differences. Journal of Drug Issues, Winter, 153-178. 
Brook, J. S., Whiteman, M., Gordon, A. S., Nomura, C., \& Brook, D. W. (1986). Onset of adolescent drinking: A longitudinal study of intrapersonal and interpersonal antecedents. Advances in Alcohol and Substance Abuse, 5, 91-110.

Bryant, A. L., Shulenberg, J. E., O'Malley, P. M., Bachman, J. G., \& Johnston L. D. (2003). How academic achievement, attitudes, and behaviors relate to the course of substance use during adolescence: A 6-year, multiwave national longitudinal study. Journal of Research on Adolescence, 13, 361-397.

Cardenal, C. A., \& Adell, M. N. (2000). Factors associated with problematic alcohol consumption in school children. Journal of Adolescent Health, 27, 425-433.

Center for Human Resource Research. (2001). The National Longitudinal Surveys NLSY79 User's Guide. Columbus, OH: Bureau of Labor Statistics, U.S. Department of Labor.

Center for Human Resource Research. (2000). The National Longitudinal Surveys NLSY79 User's Guide. Columbus, OH: Bureau of Labor Statistics, U.S. Department of Labor.

Conger, R. D., \& Rueter, M. A. (1996). Siblings, parents, and peers: A longitudinal study of social influences in adolescent risk for alcohol use and abuse. In G. H. Brody (Ed.), Sibling relationships: Their causes and consequences (pp. 1-30). Westport, CT: Ablex.

Cumsille, P. E., Sayer, A. G., \& Graham, J.W. (2000). Perceived exposure to peer and adult drinking as predictors of growth in positive alcohol expectancies during adolescence. Journal of Consulting and Clinical Psychology, 68, 531-536.

Dinges, M. M., \& Oetting, E. R. (1993). Similarity in drug use patterns between adolescents and their friends. Adolescence, 28, 253-266.

Epstein, J. A., Botvin, G. J., Baker, E., \& Diaz, T. (1999). Impact of social influences and problem behavior on alcohol use among inner-city Hispanic and Black adolescents. Journal of Studies on Alcohol, 60, 595-604.

Epstein, J. A., Botvin, G. J., \& Diaz, T. (1995). The role of social factors and individual characteristics in promoting alcohol use among inner-city minority youths. Journal of Studies on Alcohol, 56, 39-46.

Fergusson, D. M., Lynskey, M. T., \& Horwood, L. J. (1996). Alcohol misuse and juvenile offending in adolescence. Addiction, 91, 483-494.

Flannery, D. J., Vazsonyi, A. T., Torquati, J., \& Fridrich, A. (1994). Ethnic and gender differences in risk for early adolescent substance use. Joumal of Youth and Adolescence, 23, 195-213.

Guo, J., Hawkins, J. D., Hill, K. G., \& Abbott, R. D. (2001). Childhood and adolescent predictors of alcohol abuse and dependence in young adulthood. Joumal of Studies on Alcohol, 62, 754-762.

Hawkins, J. D., Catalano, R. F., \& Milter, J. Y. (1992). Risk and protective factors for alcohol and other drug problems in adolescence and early adulthood: Implications for substance abuse prevention. Psychological Bulletin, 112, 64-105.

Johnston, L. D., O’Malley, P. M., \& Bachman, J. G. (1999). National survey results on drug use from the monitoring the future study, 1975-1998. U.S. Department of Health and Human Services.

Kandel, D. B., \& Andrews, K. (1987). Processes of adolescent socialization by parents and peers. The International Journal of the Addictions, 22, 319-342. 
Kaplow, J. B., Curran, P. J., Dodge, K. A., \& the Conduct Problems Prevention Research Group. (2002). Child, parent, and peer predictors of early-onset substance use: A multisite longitudinal study. Journal of Abnormal Psychology, 30, 199-216.

Ledoux, S., Miller, P., Choquet, M., \& Plant, M. (2002). Family structure, parent-child relationships, and alcohol and other drug use among teenagers in France and the United Kingdom. Alcohol and Alcoholism, 37, 52-60.

Lo, C. C. (2000). Timing of drinking initiation: A trend study predicting drug use among high school seniors. Journal of Drug Issues, 30, 525-554.

Mason, W.Z., \& Windle, M. (2001). Family, religious, school and peer influences on adolescent alcohol use: A longitudinal study. Journal of Studies on Alcohol, 62, 44-53.

O'Malley, P. M., Jolnnston, L. D., \& Bachman, J. G. (1998). Alcohol use among adolescents. Alcohol Health \& Research World, 22, 85-93.

Paschall, M. J., Flewelling, R. L., \& Faulkner, D. L. (2000). Alcohol misuse in youth adulthood: Effects of race, educational attainment, and social context. Substance Use \& Misuse, 35, 1485-1506.

Petraitis, J., Flay, B. R., \& Miller, T. Q. (1995). Reviewing theories of adolescent substance use: Organizing pieces in the puzzle. Psychological Bulletin, 117, 67-86.

Steinberg, L., \& Silverberg, S. B. (1986). The vicissitudes of autonomy in early adolescence. Child Development, 57(4), 841-851.

Strycker, L. A., Duncan, S. C., \& Pickering, M. A. (2003). The social context of alcohol initiation among African American and White youth. Journal of Ethnicity in Substance Use, 2(1), 35-42.

Substance Abuse and Mental Health Services Administration. (2002). Summary of Findings from the 2000 National Household Survey on Drug Abuse. DHHS Publication. Rockville, MD.

Thomas, G., Reifman, A., Barnes, C. M., \& Farrell, M. P. (2000). Delayed onset of drunkenness as a protective factor for adolescent alcohol misuse and sexual risk taking: A longitudinal study. Deviant Behavior, 21, 181-210.

Wills, T. A., \& Yaeger, A. M. (2003). Family factors and adolescent substance use: Models and mechanisms. Current Directions in Psychological Science, 12(6), 222-226.

Windle, M. (1996). Effect of parental drinking on adolescents. Alcohol Health and Research World, 20, 181-184.

Zhang, L., Wieczorek, W. F., \& Welte, J. W. (1997). The impact of age of onset of substance use on delinquency. Journal of Research in Crime and Delinquency, 34, 25.3-268.

doi:10.1300/J029v16n02_05 